\title{
Factors That Influence Optimization Open Space Under the Jenggolo Sidoarjo Flyover
}

\author{
S H Laksono ${ }^{1}$ and V G P J Paryoko ${ }^{2}$ \\ ${ }^{1}$ Architecture Departement, Institut Teknologi Adhi Tama Surabaya, Indonesia \\ ${ }^{2}$ Architecture Departement, Merdeka University,Surabaya, Indonesia \\ sigitarci@gmail.com
}

\begin{abstract}
Population in Surabaya and Sidoarjo grows rapidly every year. The need for open space is increasing from the needs of residences, shops, hotels, malls, and so on, so that almost every open space in every area is utilized both by legal buildings and illegal buildings or activities. The emergence of illegal activities in areas that are not utilized such as commensurate environmental lines, under flyovers, and around the banks of rivers, can cause the growth and structuring of the city to be hampered. The location of this research paper is under the Jenggolo Sidoarjo flyover, and it is known that there is an irregularity in the arrangement of both street vendors, open spaces, parks and there is still plenty of free space on the site. So as to support the government's efforts in correct and optimal spatial planning and cities. The paper that will be discussed is how to know the potential and ways to develop existing potentials into a public space that is sensitive to public and surrounding environment. So that the public space created is expected to be able to support the arrangement of space and the city of Sidoarjo in particular.
\end{abstract}

\section{Introduction}

Many areas under this flyover are not yet optimally utilized, for example, there are several areas that are used as places for street vendors to sell, where scavengers live, where to park, and many others. Besides that, the condition of land that looks shabby and prone to crime makes a negative value for the development of the city. All of these phenomena occur because there is no plan that really pays attention to the potential of the area. But what needs to be considered is that there are several different types of space created under the flyover, there are those that have the potential as public spaces and some that do not. Therefore the research that will be carried out here is to make an exploration of the design of public spaces and city parks under an flyover that adapted from the results of surveys and literature studies from several examples of existing flyovers. From the phenomena that have been explained, it also happened at the research location, even though the area under the Jenggolo Sidoarjo flyover already contained arrangements both from the street vendors and the open space, but it looked less than optimal. This phenomenon can be seen from the fact that there is still a lot of vacant space left untreated, the arrangement of street vendors that looks less neat, making public spaces less clear, and at night this place is prone to crime. When viewed in the research locations described above, then to develop public spaces and city parks under flyovers into useful public spaces, it is necessary to study the characteristics of the existing elements of open spaces and city parks. 


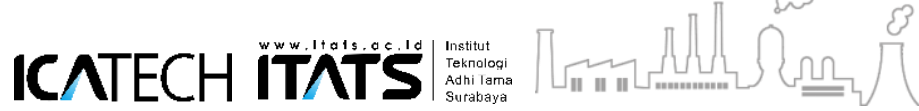

The $1^{\text {st }}$ International Conference on Advanced Engineering and Technology - 2018

\section{Literature Study}

\subsection{Behavioral Architecture}

According to Snyder and Catanese (1984), behavior-oriented architecture is an architecture that is able to respond to human needs and feelings that adjust to the lifestyle of humans in it. According to Clovis Heimsath, AIA (1988), the word "behavior" expresses an awareness of the social structure of people, a dynamic movement together in time. Just by thinking of a person's behavior in space then we can make a design.

Behavioral architecture is architecture which in its application always include behavioral considerations in designing behavioral link with architecture design (as physical environment) that architecture design can become facilitator of behavior or vice versa as barrier of behavior (JB Watson, 1878-1958).

\subsection{Public Space}

The definition of public space is a public place where people carry out routine and functional activities that bind a community, both in the normal routine of everyday life, as well as in periodic celebrations [1].

In designing the public space must be in accordance with the context, because every public space design is a good expression of the culture, behavior, habits, needs, history, and psychology of the surrounding community.

\subsection{Area under Flyover}

The space at the bottom of the flyover is the space created by the overpass. In accordance with government regulations, spaces under flyovers are generally included in the RTNH (Non-Green Open Space) category, especially in locations with hardened surfaces or not overgrown plants. Even though the space under the flyover is included in the RTNH, however, specifically for this type of RTNH, the amount of provision is not regulated in government regulations. The space below the flyover generally has a surface made of pavement, so it is included in the RTNH category. Although including RTNH, many cases of space under flyovers are not used for activities. This is related to efforts to maintain security and order in urban areas. Space under flyovers is mainly used for certain ecological support areas. In accordance with the Guidelines for Provision and Utilization of Green Open Space, the space created under flyovers should ideally be equipped with certain vegetation elements that can live with limited sunlight, using pots or tanks that can also be RTNH. The aim is to increase the beauty of the area under the flyover.

\section{Methode}

The research used in this study used qualitative descriptive method [2]. The aim is to make the description, description or painting systematically, factually and accurately about the facts, properties and relationships between the phenomena studied.The stages of his research as follows: Identify potential sites physically and non physically. This process includes site surveys, observation, interviews, and sorting of existing data. Formulate design criteria as reference in design development. In formulating the criteria here is used walkthrought analysis analysis that functioned to know all the potential and activities visually visible, and then proceed with SWOT analysis to know the advantages, weaknesses, opportunities, and threats that exist. Formulate the design concept of Design and Design of thematic park area. Planning strategies that have been obtained from the SWOT results can be used as criteria that will be drawn the design concept. 


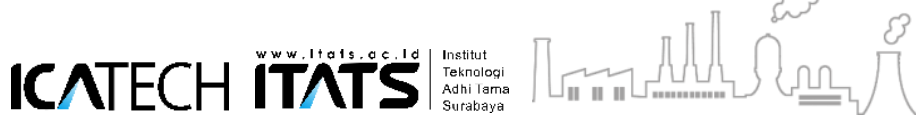

The $1^{\text {st }}$ International Conference on Advanced Engineering and Technology - 2018

\section{Discussion}

\subsection{The location and nature of the open space under the Jenggolo Sidoarjo flyover}

One of the uses of public open space here is influenced by the location and type of the flyover. When viewed from the location, the open space area is created because it is under the overpass and is limited by a turning road under the overpassWhereas for this type of area is an area that is indeed possible for a public activity, because the transportation that is on the turntable has a low intensity, in other words the area is not too dense and the average speed of the vehicle is around $20 \mathrm{~km} /$ hour.

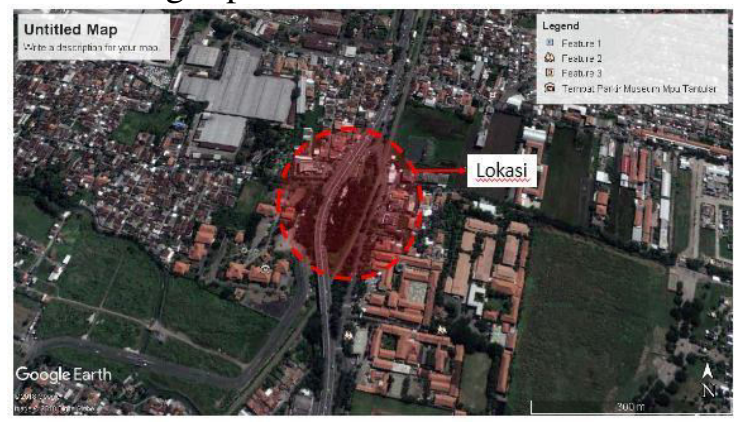

Figure 1. Map of open space under the Jenggolo Sidarjo flyover (Google Earth, 2018)

With these conditions so that at present and before, in this area there are many street vendors both those that are on the road and those in the open space. For this type of vehicle that crosses the turning road, there are large truck, bus, car and motorbike vehicles. In addition to the backlash conditions that are not too crowded, there are other things that trigger public activity and the existence of the street vendors, namely the presence of open green space adjacent to the overpass area.

The entry area is a green space that has been processed into a semi-active park, can be seen from the presence of statues, fountains and pedestrian tracks. Although the processed green space is only a small part, it is able to trigger a public activity. And the emergence and development of existing public activities is not balanced by adequate arrangement, so that up to now the existing RTH and PKL conditions have not run optimally.

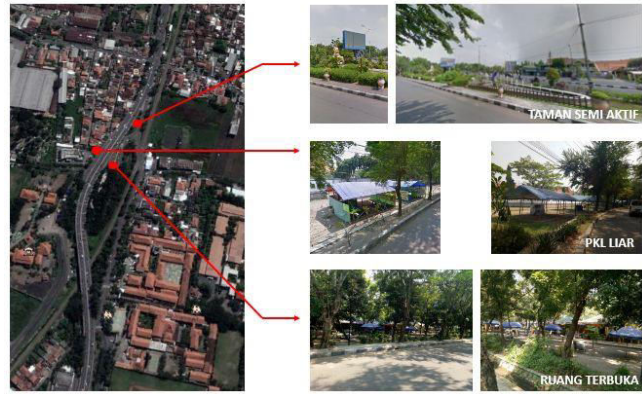

Figure 2. Map of open space under the Jenggolo Sidarjo flyover (Personal Data, 2018) 


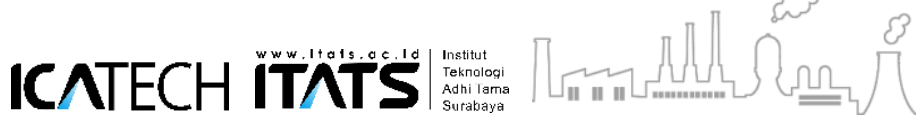

The $1^{\text {st }}$ International Conference on Advanced Engineering and Technology - 2018

\subsection{PKL (Street Vendor)}

In the existing condition, the most visible thing is the growth of street vendors, before 2016, this area had a lot of wild street vendors selling both on the shoulder of the road and in open spaces that were not utilized. In early 2016 the Sidoarjo regency government began to regulate sellers who did not have a business permit by making the PKL centers in the open area under the overpass.
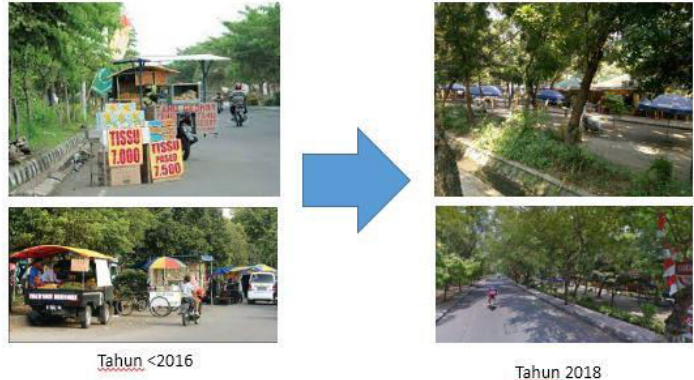

Tahun 2018

Figure 3. PKL activities before and after curbing (Personal Data, 2018)

However, after running for 2 years, the condition of street vendors was not much different from the activities before 2016. This can be seen from the operational time when selling is not crowded at all times, there is no open space arrangement, many open lands are used as illegal PKL development, there is no integration of activities and surrounding buildings.

\subsection{Green and Non Green Open Space}

In this area there are many open areas both that are RTH and RTNH. RTNH in this area is located just below the overpass, where the current condition of the area has not been utilized properly. While for $\mathrm{RTH}$, there are around RTNH under the bridge. At present the existing green open space looks less organized, where the dominant green open space is only in the form of weeds and trees, there is no specificity in the arrangement. However, there are some areas of green open space that have been processed, namely in the area adjacent to the overpass area, where this area was made before 2016 as a sign of welcome in Sidoarjo regency.

\subsection{Building Function}

There are several functions of buildings that are around this area, including the Mpu Tantular Museum, Shops, High Schools, and Vocational High Schools. So that if it is categorized in a building function, there are functions of educational buildings and also functions of commercial buildings.
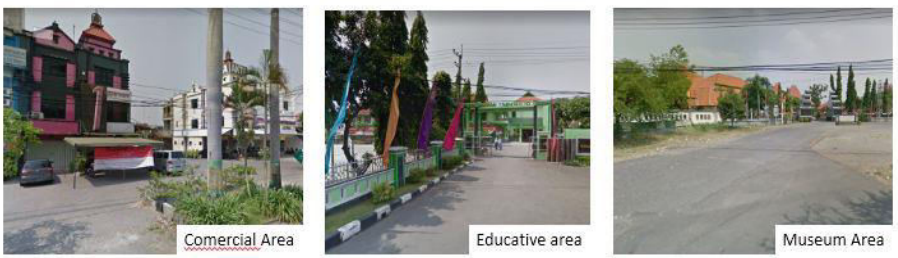

Figure 3. Building functions around the site (Personal data, 2018)

Of the several buildings that are located around the open space area, this open space area must have an integration of activities in the surrounding buildings. In the existing condition, the existing open space seems to have only been used to move the street vendors who used to be on the shoulder of the road to move to an area in a green open space. So that the condition of this open space still looks shabby and prone to crime at night due to the lack of lighting conditions in the area.

Educational Building Function, there are two schools that are located around this open space, where the existence of the school has an influence on this open space, not a positive influence but a negative influence, this can be seen by the use of open space as a parking space for students. From this 


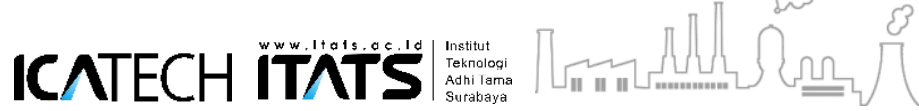

The $1^{\text {st }}$ International Conference on Advanced Engineering and Technology - 2018

phenomenon it can be seen that the use of open space is not right on target, where the open space is planned to be a space that can support the activities of teaching and learning activities and not as a residual space.

Comercial Building Function, for commercial buildings in this area there is no effect on the physical open space, because each shop has its own parking lot corridor. However, another influence that can be seen is that the existence of this shop can trigger many visitors in this area..

\section{Open Space Design.}

When viewed from the order and land use there are several problems, including scattered street vendor zoning, pedestrian zoning which is not clear, confusion between street vendors and green open space, unclear pedestrian pedestrian, RTNH area under the bridge which is not utilized and part of the area is used as a parking lot.

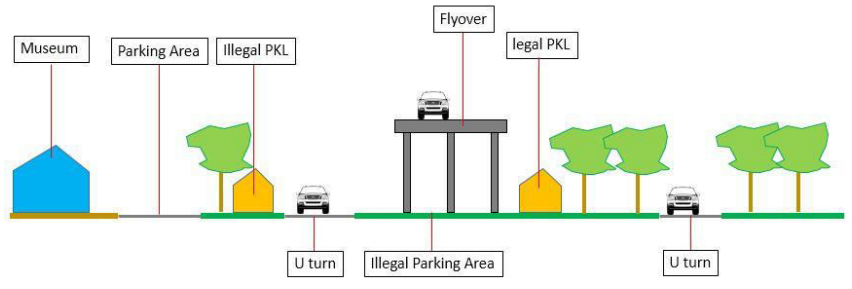

Figure 4. Section building functions around the site (Personal data, 2018)

When viewed in terms of architecture, the design of this open space lacks sensitivity to the behavior of the user community, there is no integration with activities around the site, visually the design of this park, both from the design of open space, public space, and street vendors does not have a strong character.

\section{Conclusion}

Based on the results of the above discussion it is known that there are several positive potentials and some are negative, so that affecting the open space becomes not optimal, there are several factors, including: The location which is under the overpass, makes the condition of this open space look shabby and dark. PKL center that has no clear area boundaries. There are still illegal PKL around the location. Non-designed green open spaces make public activities in this area not optimal. The existing RTNH is left empty, it seems rundown, and some of it is made of illegal parking. The absence of integrations with buildings and activities around them makes this open space has no character. There is no clarity on the visual design and use of the land. As for the potential that exists, among others: Location has the potential to be developed into a city park with PKL as a supporter of public activities. The location in the middle of the city with the intensity of vehicles that are not dense, making this area very safe and potentially if used as a public space. In this area can potentially be used as an urban park with an educational perspective, because this area is close to schools and museums. By knowing the factors that influence ineffectiveness, and some of the potential sites that exist, it is expected to be a basis for consideration in improving the design of the open space to be more optimal in its utilization.

\section{Refences}

[1] M. A. Carr, S., Francis, M., Rivlin, G. L., \& Stone, Public Space. Australia: Press Syndicate of the University of Cambridge, 1992.

[2] D. Wang and L. N. Groat, Architectural research methods. Hoboken, New Jersey: John Wiley \& Sons, Inc, 2013. 